\title{
Effects of Pine Bark Extract on Physicochemical Properties and Biological Activity of Active Chitosan Film by Bionic Structure of Dragonfly Wing
}

\author{
Kang Wan ${ }^{1}$, Mengdi Cong ${ }^{1}$, Xu Teng ${ }^{1}$, Miao Feng ${ }^{2}$, Lili Ren ${ }^{3}\left(\mathbb{D}\right.$ and Liyan Wang ${ }^{1, *(D)}$ \\ 1 College of Food Science and Engineering, Jilin Agricultural University, 2888 Xincheng Street, \\ Changchun 130118, China; wankang@jlau.edu.cn (K.W.); congmengdi@foxmail.com (M.C.); \\ 20200729@mails.jlau.edu.cn (X.T.) \\ 2 College of Marxism, ChangChun Polytechnic, 3278 Weixing Road, Changchun 130033, China; \\ FengMiao0530@foxmail.com \\ 3 Key Laboratory of Bionic Engineering (Ministry of Education), College of Biological and Agricultural \\ Engineering, Jilin University, 5988 Renmin Street, Changchun 130022, China; liliren@jlu.edu.cn \\ * Correspondence: wangliyan@jlau.edu.cn; Tel.: +86-158-4301-5766
}

check for updates

Citation: Wan, K.; Cong, M.; Teng, X.; Feng, M.; Ren, L.; Wang, L. Effects of Pine Bark Extract on Physicochemical Properties and Biological Activity of Active Chitosan Film by Bionic Structure of Dragonfly Wing. Coatings 2021, 11, 1077. https://doi.org/ 10.3390/coatings11091077

Academic Editor: Fengwei

(David) Xie

Received: 18 August 2021

Accepted: 3 September 2021

Published: 6 September 2021

Publisher's Note: MDPI stays neutral with regard to jurisdictional claims in published maps and institutional affiliations.

Copyright: (c) 2021 by the authors. Licensee MDPI, Basel, Switzerland. This article is an open access article distributed under the terms and conditions of the Creative Commons Attribution (CC BY) license (https:/ / creativecommons.org/licenses/by/ $4.0 /)$.

\begin{abstract}
Bionic and active films based on chitosan were developed with the bionic structure of dragonfly wings incorporating pine bark extract (PBE). Physicochemical properties of the films, including thickness, opacity, moisture content, color, mechanical properties, and water vapor permeability were measured. Antioxidant activity of the films was characterized by DPPH free radical scavenging activity. The interaction between chitosan and PBE was explored by attenuated total reflectance Fourier transform infrared spectrometry, $X$-ray diffraction, and differential scanning calorimetry. The results indicated that the addition of PBE gave rise to the films greater opacity, redness, and darker appearance. Compared with pure chitosan film, the thickness, opacity, mechanical properties, and oxidation resistance of the bionic chitosan-PBE film increased, and the water vapor permeability decreased. The films based on chitosan incorporated PBE and with the bionic structure of dragonfly wings can potentially be applied to food packaging.
\end{abstract}

Keywords: chitosan; pine bark extract; bionic structure; film

\section{Introduction}

Plastic food packaging materials are mostly non-degradable, resulting in serious environmental pollution. The World Health Organization has reported that about 8 million tons of plastic waste enter the ocean every year, which has a serious impact on the ocean and marine life and potential impact on human health [1]. Meanwhile, microbial contamination and oxidation are the main problems affecting food quality and safety [2]. Therefore, it is necessary to develop biodegradable food packaging films with antibacterial and antioxidant properties [3].

Chitosan (Figure 1A) is a natural polysaccharide, which is yielded by partial deacetylation of chitin [4]. Chitosan possesses various features, such as biodegradability, filmforming properties, and biocompatibility, and becomes one of the research hotspots in food packaging materials [5-7]. However, pure chitosan has the disadvantage of poor antibacterial and antioxidant properties [8,9], so natural active ingredients are often incorporated to improve the antibacterial or antioxidant properties of chitosan, such as pomegranate peel extract and Thymus kotschyanus essential oil [10], chestnut extract [11], and litchi peel extract [12]. 
(A)

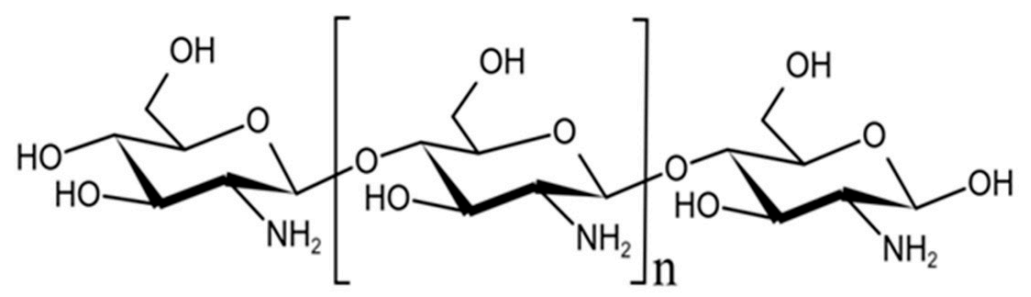

(B)<smiles>CC(C)c1c(O)cc(O)c2c1OC(c1ccc(O)c(O)c1)C(O)C2C1(C)c2c(O)cc(O)cc2CC(O)C1c1ccc(O)c(O)c1</smiles>

Figure 1. Chemical structures of chitosan (A) and proanthocyanidins (B).

Pine bark extract (PBE) has a long history of use in Europe and North America [13]. PBE contains a variety of active ingredients, mainly including proanthocyanidins (Figure 1B) composed of catechins and epicatechin subunits. These ingredients have a wide range of biological and pharmacological activities, such as antioxidant, promoting wound healing, anti-inflammatory and so on [13-15]. Nevertheless, there are fewer reports on food packaging materials with PBE.

In this study, active films from chitosan incorporated PBE and with bionic structure of dragonfly wings were developed. The physiochemical, structural, and biological properties of the bionic chitosan-PBE film was evaluated.

\section{Materials and Methods}

\subsection{Materials}

Chitosan (deacetylation $\geq 95 \%, \mathrm{Mw}=700,000-100,000,50-200 \mathrm{mPa} . \mathrm{s}$ ) was purchased from Dalian Meilun Biotechnology Co., Ltd., China (Dalian, China). Pine bark extract (PBE) was purchased from RuiHerb Bio-Engineering Technology Co., Ltd., China (Xi'an, China). The PBE was brownish red, and the content of proanthocyanidins was $\geq 95 \%$. 2,2-diphenyl1-picrylhydrazyl (DPPH) was purchased from Sigma-Aldrich Company (St. Louis, MI, USA). All reagents used were of analytical grade.

\subsection{Preparation of Negative Replica of Dragonfly Wings}

Bio-template method was used to prepare negative replica of dragonfly wings. Firstly, dragonfly wings were put in an ultrasonic cleaner for $30 \mathrm{~min}$, then remover into an oven at $60^{\circ} \mathrm{C}$ for $30 \mathrm{~min}$. After that, dragonfly wings were fastened with double-sided adhesive tape on the glass plate and arrange the dragonfly wings as closely as possible. PDMS 
solution $(200 \mathrm{~g}$ ) was poured on the plate (diameter $16 \mathrm{~cm}$ ), then the plate was place in a vacuum drying oven for 20 min until all bubbles are discharged. Finally, the plate was placed in an oven at $70^{\circ} \mathrm{C}$ for $5 \mathrm{~h}$. After the PDMS solidified, it was carefully peeled off from the plate, then the negative replica of the dragonfly wings was obtained.

\subsection{Preparation of Bionic Chitosan-PBE Film}

Chitosan solution (4 wt \%) was prepared by dissolving chitosan in $2 \%(V / V)$ acetic acid aqueous solution and stirring at $600 \mathrm{rpm}$ for $30 \mathrm{~min}$ at $60{ }^{\circ} \mathrm{C}$. Glycerin with a concentration of $30 \%$ by weight of chitosan was added to the chitosan solution as a plasticizer. Different concentrations of PBE solutions were prepared by mixing PBE and distilled water at $50{ }^{\circ} \mathrm{C}$ and stirred at $200 \mathrm{rpm}$ for $15 \mathrm{~min}$. Chitosan solution containing PBE with the concentration (weight percentage) of $30 \%, 40 \%$, and $50 \%$ was prepared by mixing chitosan solution and PBE solution in a 1:1 weight ratio and stirred at $400 \mathrm{rpm}$ for $15 \mathrm{~min}$. After removing bubbles by ultrasonic wave for $15 \mathrm{~min}$, film solution $(50 \mathrm{~g})$ was distributed into the negative replica of the dragonfly wings for casting and fix it with a stainless-steel ring with a diameter of 9 $\mathrm{cm}$ and soft glue. After drying at $60{ }^{\circ} \mathrm{C}$ and $30 \% \mathrm{RH}$, the film was peeled off and stored in a $75 \%$ relative humidity and room temperature environment for $48 \mathrm{~h}$. The chitosan film without bionic structure and PBE was used as the control. The bionic chitosan-PBE films with concentration of $0 \%, 30 \%, 40 \%$, and $50 \%$ named $\mathrm{B}-0 \% \mathrm{PBE}, \mathrm{B}-30 \% \mathrm{PBE}, \mathrm{B}-40 \% \mathrm{PBE}$, and B-50\%PBE, respectively.

\subsection{Characterization}

\subsubsection{Scanning Electron Microscopy (SEM)}

The microstructure of film samples was observed by Zeiss-evo18 SEM (Carl Zeiss Co., Ltd., Shanghai, China) with $10 \mathrm{kV}$ of acceleration voltage.

\subsubsection{Attenuated Total Reflectance-Fourier Transform Infrared Analysis (ATR-FTIR)}

ATR-FTIR spectra of film samples was determined by using a Nicolet iS50 FTIR Spectrometer couple with an ATR attachment (Nicolet, Waltham, MA, USA). The scans were carried out in range of $4000-400 \mathrm{~cm}^{-1}$ with 64 scans and a resolution of $4 \mathrm{~cm}^{-1}$.

\subsubsection{X-ray Diffraction (XRD)}

The XRD analysis was carried out in a SmartLab 3 KW diffractometer (Rigaku, Tokyo Japan), using Cu-X radiation at a voltage of $40 \mathrm{kV}$ and a current of $40 \mathrm{~mA}$. Film samples were measured at a scan rate of $2^{\circ} / \mathrm{min}$ within $2 \theta$ range $\left(5-40^{\circ}\right)$ according to the method of Wang et al. [16].

\subsubsection{DPPH Free Radical Scavenging Activity}

The DPPH free radical scavenging activity of film samples was determined according the method of Wang et al. [17]. With some alteration, $9 \mathrm{~mL}$ of film samples extract solution was mixed with $3 \mathrm{~mL}$ of DPPH $10^{-3} \mathrm{~mol} / \mathrm{L}$ ethanol solution, then shaken in an oscillator for $30 \mathrm{~s}$, incubated in dark room for $30 \mathrm{~min}$ at room temperature and measured at $517 \mathrm{~nm}$ using UV spectrophotometer. DPPH scavenging activity was calculated based on the following equation:

$$
\text { DPPH scavening activity }(\%)=\frac{A_{\mathrm{DPPH}}-A_{\mathrm{S}}}{A_{\mathrm{DPPH}}} \times 100
$$

where $A_{\mathrm{DPPH}}$ is the absorbance value of the DPPH methanol solution and $A_{\mathrm{S}}$ is the absorbance value of the DPPH assay solution.

\subsubsection{Water Vapor Permeability (WVP)}

The WVP of film samples was measured using the method of Bai et al. [18]. 


\subsubsection{Thickness, Opacity, and Moisture Content}

The thickness of the films was determined by using a hand-held digital micrometer (EVERTE, Henan, China) at five random positions, then the average values were taken.

Opacity of the films was determined by measuring the absorbance of film samples at $600 \mathrm{~nm}$ using a UV spectrophotometer (Model Lambda 365, PerkinElmer, Waltham, MA, USA) according to the method of wang et al. [19]. Films were cut into slices $(1 \times 4 \mathrm{~cm})$, then placed in a spectrophotometer test cell. An empty test cell was used as the reference. The opacity was calculated based on the following Equation:

$$
O=\frac{A b s_{600}}{d}
$$

where $O$ is the opacity, $A b_{600}$ is the value of absorbance at $600 \mathrm{~nm}$, and $d$ is the films thickness (mm).

The moisture content of the film samples was measured by placing the films $(1 \times 4 \mathrm{~cm})$ in an oven at $105{ }^{\circ} \mathrm{C}$ for $12 \mathrm{~h}$. Then the moisture content of each sample was calculated according to the following Equation:

$$
\text { Moisture content }(\%)=\frac{M_{\mathrm{w}}-M_{\mathrm{d}}}{M_{\mathrm{w}}} \times 100 \%
$$

where $M_{\mathrm{w}}$ is the weight of the films in $75 \% \mathrm{RH}$ and $M_{\mathrm{d}}$ is dry weight of the films.

\subsubsection{Mechanical Properties}

The tensile strength (TS) and elongation at break (EAB) of the film samples $(10 \times 40 \mathrm{~mm})$ were measured using a texture analyzer machine (WDW-200H, Jinan HengXu Testing Machine Technology Co., Ltd., Jinan, China) at a crosshead speed of $50 \mathrm{~mm} / \mathrm{min}$.

\subsubsection{Color Properties}

The color values of the film samples were determined by using a chromometer with a $14 \mathrm{~mm}$ aperture (HunterLab ColorFlex, Shanghai, China), a D65 illuminant and a $10^{\circ}$ angle. Prior to analysis, the chromometer was calibrated with a standard plate CX2064. Then film samples were subjected to chromometer for lightness ( $L^{*}$-value), redness ( $a^{*}$-value), and yellowness ( $b^{*}$-value). $\Delta E$ and $C$ were calculated as follows:

$$
\begin{gathered}
\Delta E=\sqrt{\left(\Delta a^{2}+\Delta b^{2}+\Delta c^{2}\right)} \\
C=\sqrt{\left(a^{2}+b^{2}\right)}
\end{gathered}
$$

where $\Delta a=a^{*}$ standard $-a^{*}$ sample, $\Delta b=b^{*}$ standard $-b^{*}$ sample, $\Delta L=L^{*}$ standard $-L^{*}$ sample.

\subsection{Statistical Analysis}

The difference among samples was evaluated by one-way analysis of variance (ANOVA). Duncan's multiple range tests were used to compare the means to identify which groups were significantly different from other groups $(p<0.05)$. Each experiment was repeated in three times and all data are presented as mean \pm standard deviation.

\section{Results and Discussion}

\subsection{Scanning Electron Microscopy (SEM)}

Scanning electron microscope can effectively observe the surface morphology and structure of films. Figure 2 presented the SEM image of the film samples surface under 3000 times magnification. The results suggested that the pure chitosan film (control) was smooth. Figure $2 \mathrm{~B}_{1}$ showed that B- $0 \%$ PBE successfully replicated the microstructure of dragonfly wings with a rough and uneven appearance. Figure $2 \mathrm{~B}_{2}$ showed that the surface 
of the B- $0 \%$ PBE film had a structure similar to the micronano structure on the surface of the dragonfly's wings, which indicated that the film had successfully bionic dragonfly wings. After incorporating PBE into a chitosan film, films only replicate the macroscopic structure of dragonfly wings. White spots on bionic chitosan-PBE films surface may be insoluble particles from PBE. At the same time, these small spots might be the reason that hinders the replication of the microstructure of the dragonfly's wings by the film.

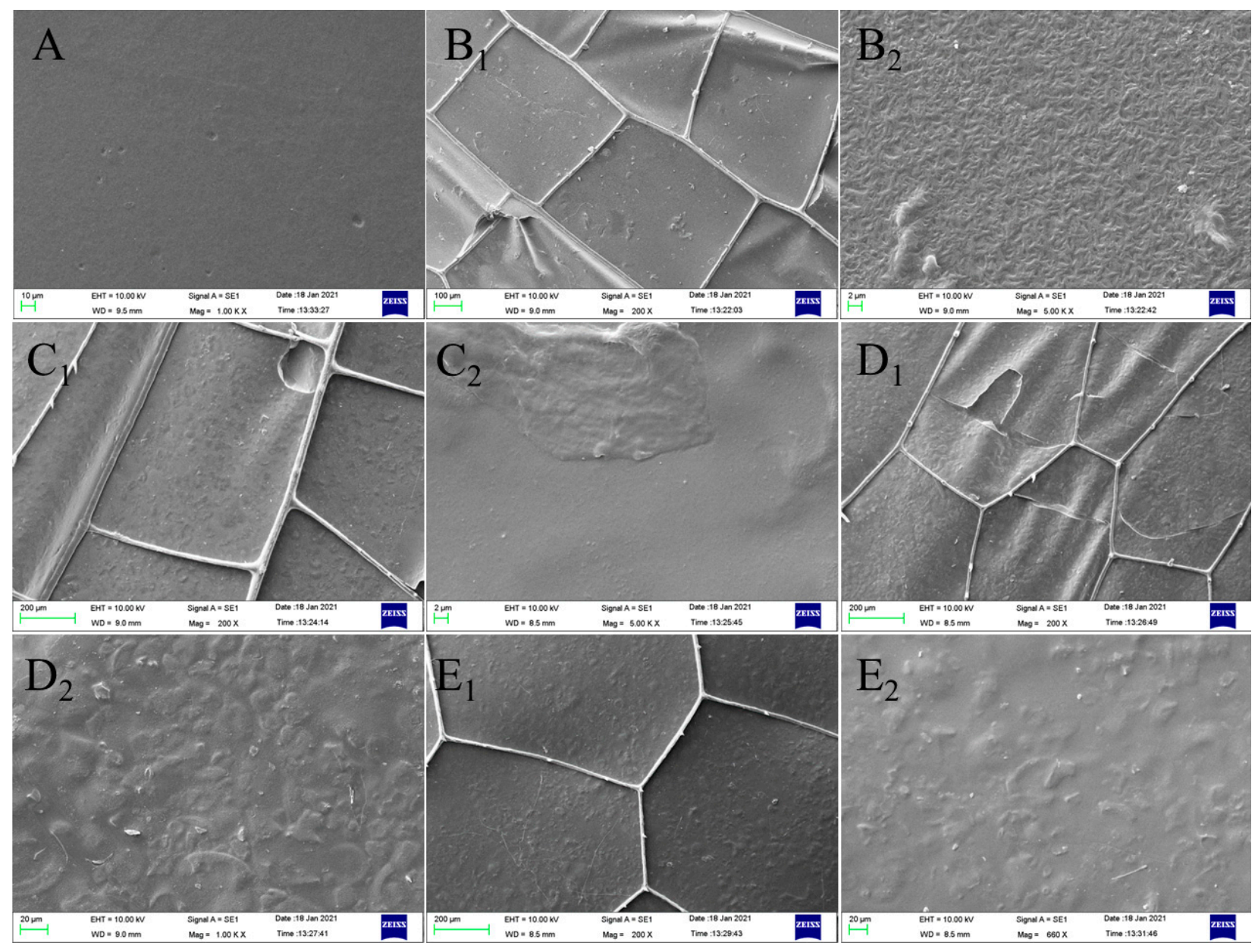

Figure 2. SEM micrographs of the control film and bionic chitosan-PBE films: (A) control film; $\left(\mathbf{B}_{1}, \mathbf{B}_{2}\right)$ B- $0 \%$ PBE films; $\left(\mathbf{C}_{\mathbf{1}}, \mathbf{C}_{\mathbf{2}}\right)$ B-30\%PBE films; $\left(\mathbf{D}_{\mathbf{1}}, \mathbf{D}_{\mathbf{2}}\right)$ B-40\%PBE films; $\left(\mathbf{E}_{\mathbf{1}}, \mathbf{E}_{2}\right)$ B-50\%PBE films.

\subsection{Attenuated Total Reflectance-Fourier Transform Infrared Analysis (ATR-FTIR)}

ATR-FTIR spectroscopy was carried out to observe the variation of transmission peaks in the bionic chitosan-PBE films, which could explain the interactions between chitosan and PBE. ATR-FTIR spectra of chitosan-PBE films were shown in Figure 3. There was no significant $(p<0.05)$ difference between the control and B- $0 \% \mathrm{PBE}$, because the two samples possessed the same composition. In addition, the ATR-FTIR spectra of bionic chitosanPBE films exhibited the same main peaks, however, the amplitudes of the peaks differed depending on the concentration of PBE. With the PBE concentration increasing, the peak at $3620,1540,1070$, and $1030 \mathrm{~cm}^{-1}$ became more and more small. When the concentrate of PBE was $50 \%$, the peak at $1070 \mathrm{~cm}^{-1}$ became more flattened and less discernible. Similar results were found by Wang et al. who prepared chitosan film with Herba Lophatheri extract [17]. In the literature, the peak at $3620 \mathrm{~cm}^{-1}$ belongs to multiple absorption peaks superimposed on the $\mathrm{O}-\mathrm{H}$ stretching vibration absorption peak and the $\mathrm{N}-\mathrm{H}$ stretching vibration absorption peak [20], the peak at $1070 \mathrm{~cm}^{-1}$ was related to $\mathrm{C}-\mathrm{O}-\mathrm{C}$ symmetric 
stretching [21]. The results suggested that the addition of PBE in chitosan films leaded to interactions between chitosan and PBE.

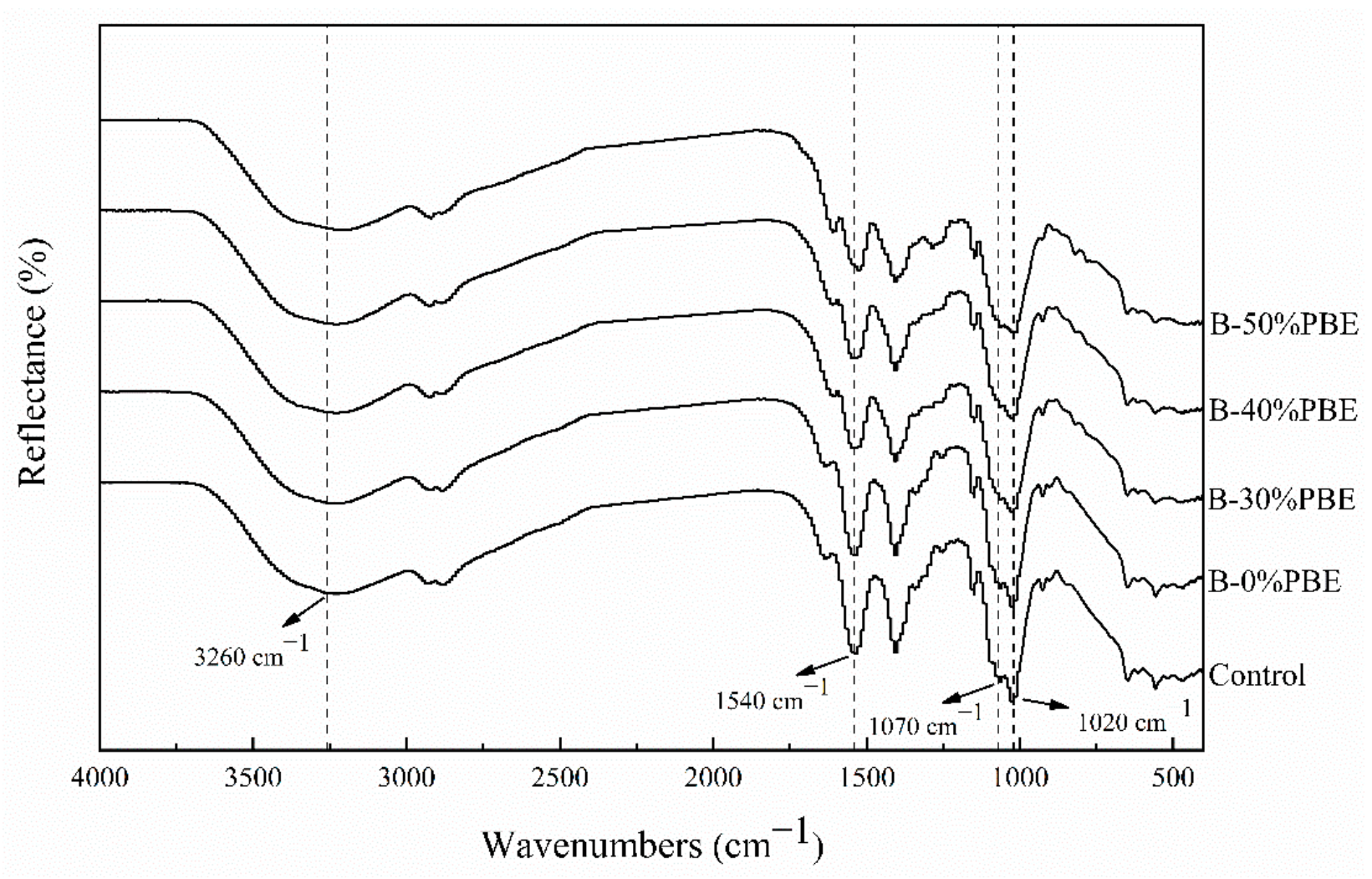

Figure 3. ATR-FTIR spectroscopy of film samples.

\subsection{X-ray Diffraction (XRD)}

The XRD diffractograms of film samples were shown in Figure 4. As seen in Figure 4, we find that the chitosan film was in crystalline state, and there were four main diffraction peaks at around $8^{\circ}, 11^{\circ}, 18^{\circ}$, and $23^{\circ}$. Similar observations were also made by Sun et al. who incorporated thinned young apple polyphenols in chitosan films [22]. The diffraction peaks at near $8^{\circ}$ and $18^{\circ}$ were ascribed to the hydrated crystalline structures [23], while the around $11^{\circ}$ peak denoted the anhydrous structure [24]. There was no significant change in the four main diffraction peaks between the control and B-0\%PBE, indicating that the bionic structure had no effect on the crystallization properties of chitosan films. After adding PBE, the peaks at around $18^{\circ}$ and $23^{\circ}$ became flatter and peak at around $8^{\circ}$ disappeared, suggesting that the crystallinity of chitosan decreased. The peak at around $23^{\circ}$ was a typical fingerprint for chitosan, and incorporated PBE in chitosan films had no changes in this peak. Similar observations were also made by Liu et al. who incorporated protocatechuic acid in chitosan films [25]. Moreover, when incorporated 50\% content in chitosan films, two small peaks at around $28^{\circ}$ and $29^{\circ}$ were appeared. It may be because the interactions between chitosan and PBE. 


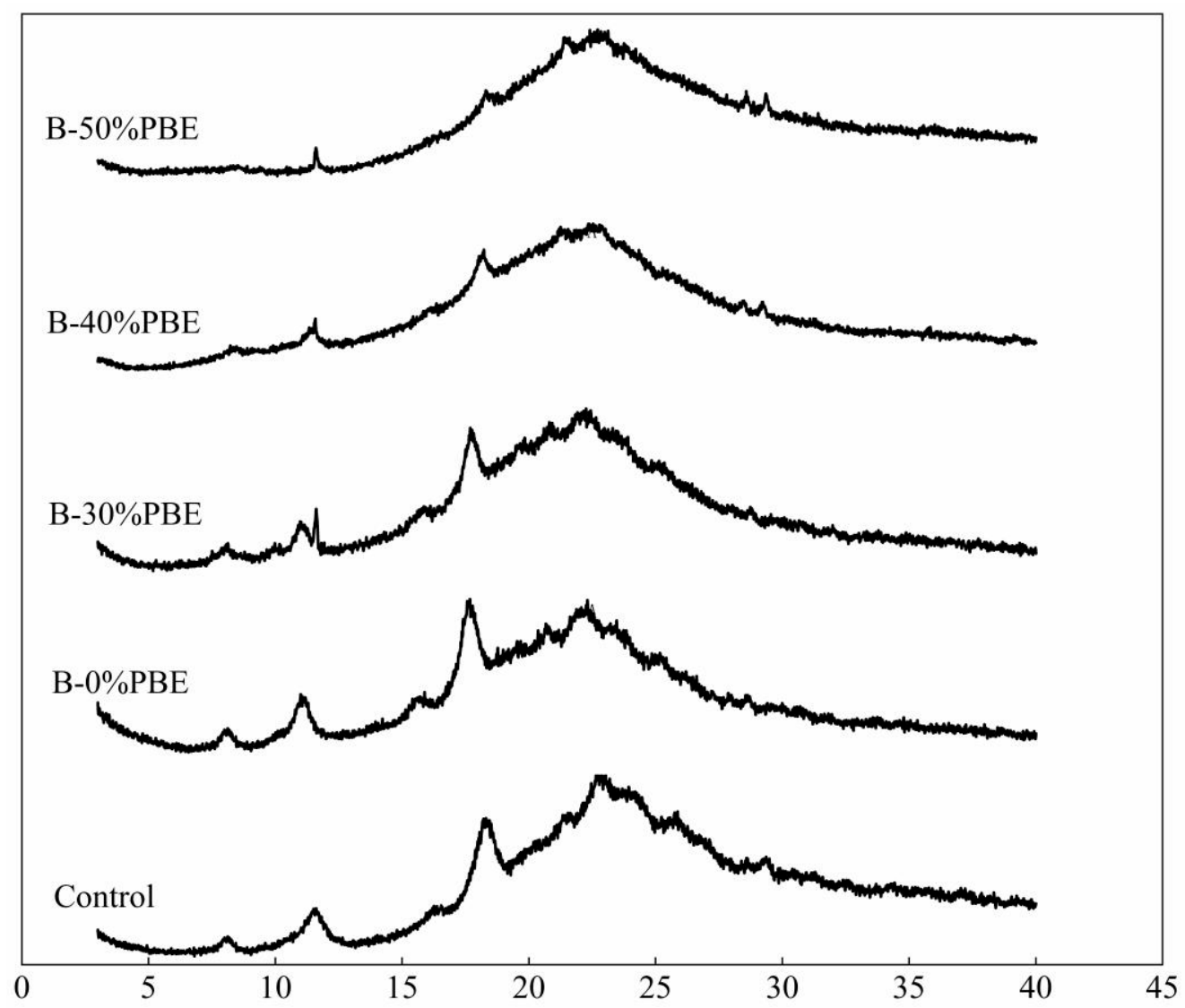

Figure 4. XRD diffractograms of film samples.

\subsection{DPPH Free Radical Scavenging Activity}

Due to the harmful effects of free radicals on foods, antioxidant activity packaging can remove free radicals and extend the shelf life of foods [26]. The DPPH free radical scavenging activity of bionic chitosan-PBE films are shown in Table 1. The free scavenging rate of pure chitosan films was weak, which was similar to the results reported by Kadam et al. [27]. There was no significant $(p<0.05)$ difference in the scavenging rate of free radicals between control and B- $0 \% \mathrm{PBE}$. The addition of PBE significantly $(p<0.05)$ improved the free radical scavenging activity of bionic chitosan-PBE films, and the free radical scavenging activity was enhanced with the increase of PBE concentration. When the concentration of PBE was $50 \%$, the free radical scavenging rate was the highest, reaching $60.56 \%$, which was about 14 times higher than that of pure chitosan film. According to the report by Romani et al., commercial packaging PE film does not possess free radical scavenging activity [28]. Therefore, compared with PE film, the bionic chitosan-PBE film in this study showed significantly $(p<0.05)$ higher free radical scavenging activity. This is because the PBE added to the film has strong antioxidant activity [14]. In addition, the DPPH free radical scavenging activity of the bionic chitosan-PBE was higher than those of chitosan films incorporated with peanut skin extract [29] and Chinese chive (Allium tuberosum) root extract [30], also indicating that PBE has good antioxidant activity and can be used for enhancing the antioxidant activity of chitosan film. 
Table 1. DPPH free radical scavenging activity and water vapor permeability of film samples.

\begin{tabular}{ccc}
\hline Films & $\begin{array}{c}\text { DPPH Free Radical } \\
\text { Scavenging Activity (\%) }\end{array}$ & $\begin{array}{c}\text { Water Vapor Permeability } \\
\mathbf{( 1 0}^{-\mathbf{1 1}} \mathbf{g ~ m}^{\mathbf{- 1}} \mathbf{~ s}^{\mathbf{- 1}} \mathbf{P a}^{\mathbf{- 1}} \mathbf{)}\end{array}$ \\
\hline Control & $4.29 \pm 0.12^{\mathrm{a}}$ & $9.43 \pm 0.51^{\mathrm{e}}$ \\
B-0\%PBE & $4.78 \pm 0.26^{\mathrm{a}}$ & $8.64 \pm 0.42^{\mathrm{d}}$ \\
B-30\%PBE & $36.25 \pm 0.59^{\mathrm{b}}$ & $6.73 \pm 0.23^{\mathrm{c}}$ \\
B-40\%PBE & $54.37 \pm 0.47^{\mathrm{c}}$ & $5.23 \pm 0.18^{\mathrm{b}}$ \\
B-50\%PBE & $60.56 \pm 0.41^{\mathrm{d}}$ & $3.82 \pm 0.20^{\mathrm{a}}$ \\
\hline
\end{tabular}

Values are given as mean \pm standard error. Different letters in the same row indicate significant differences $(p<0.05)$.

\subsection{Water Vapor Permeability (WVP)}

One of the most important functions of food packaging film is to hinder the exchange of moisture between the atmosphere and the food [31]. The WVP values of bionic chitosanPBE films were shown in Table 1 . The WVP of B-0\%PBE was lower $(8.38 \%)$ than that of control, indicating that the bionic structure decreased the WVP of the chitosan film, because the bionic structure increased the thickness of films and hindered the permeation of moisture. The WVP of the bionic chitosan-PBE films decreased significantly $(p<0.05)$ with the increasing PBE concentration. Compared with B- $0 \% \mathrm{PBE}$, WVP of B-30\% PBE, B- $40 \% \mathrm{PBE}$, and B-50\%PBE decreased $28.63 \%, 44.54 \%$, and $59.49 \%$. This downward trend was beneficial to the preservation of food, which was consistent with the reported by Wang et al. [32]. In addition, the WVP values of bionic chitosan-PBE were lower than those of chitosan film incorporated with protocatechuic acid [25] and carboxymethyl chitosan film incorporated with quercetin [18].

Generally, WVP depends on the diffusivity and solubility of water molecules in the film matrix [15]. As shown in Table 2, the addition of PBE increased the thickness of the film and filled the structural gap in the polysaccharide chain, so it reduced the gap space in the chitosan matrix, blocked the transmission channel of water in the film and reduced the diffusion and fusion rate of water molecules in the films [33]. Meanwhile, ATR-FTIR spectra showed that the interaction between chitosan and PBE may be one of the reasons for the decrease of WVP of bionic chitosan-PBE film, which may reduce the effectiveness of the hydrophilic groups in chitosan and their interaction with water.

Table 2. Thickness, opacity, and moisture content of film samples.

\begin{tabular}{cccc}
\hline Films & Thickness $(\mathbf{m m})$ & Opacity $^{\left(\text {Amm }^{-1}\right)}$ & Moisture Content (\%) \\
\hline Control & $0.2749 \pm 0.017^{\mathrm{a}}$ & $0.689 \pm 0.073^{\mathrm{a}}$ & $47.28 \pm 3.19^{\mathrm{d}}$ \\
B-0\%PBE & $0.3578 \pm 0.048^{\mathrm{b}}$ & $2.035 \pm 0.371^{\mathrm{b}}$ & $43.25 \pm 1.78^{\mathrm{c}}$ \\
B-30\%PBE & $0.4307 \pm 0.004^{\mathrm{c}}$ & $5.129 \pm 0.145^{\mathrm{c}}$ & $34.18 \pm 0.69^{\mathrm{b}}$ \\
B-40\%PBE & $0.4460 \pm 0.036^{\mathrm{c}}$ & $5.948 \pm 0.185^{\mathrm{d}}$ & $30.42 \pm 0.66^{\mathrm{ab}}$ \\
B-50\%PBE & $0.4625 \pm 0.043^{\mathrm{c}}$ & $7.104 \pm 0.791^{\mathrm{e}}$ & $28.31 \pm 2.86^{\mathrm{a}}$ \\
\hline
\end{tabular}

Values are given as mean \pm standard error. Different letters in the same row indicate significant differences $(p<0.05)$.

\subsection{Thickness, Opacity and Moisture Content}

The thickness, opacity, and moisture content of the bionic chitosan-PBE films was displayed in Table 2. The thickness of B- $0 \% \mathrm{PBE}$ was higher than the control, since there were a lot of small humps on the surface of the bionic film. With the increase of the PBE content, the thickness of bionic chitosan-PBE films was increased due to the addition of PBE. Similarly, Kadam et al. reported that the thickness of chitosan film samples with the addition of pine needles extract was higher than that of the pure chitosan films [27].

The bionic design and the addition of PBE significantly $(p<0.05)$ increased the opacity of the film samples; one reason for this was that the bionic structure increased the thickness of the film, another reason was that the PBE had brownish red color. In the literature, Riaz et al. report that apple peel polyphenols also improved the opacity of the chitosan film [34]. 
According to Equation (2), larger $O$ values indicate higher opacity and lower transparency. Therefore, the control (without PBE and bionic structure) had the highest transparency, chitosan film with bionic structure had lower transparency, and bionic chitosan-PBE film had the lowest transparency.

As shown in Table 2, we can find that the bionic structure and PBE content had a significant $(p<0.05)$ impact on the moisture content of the film. Compared with the control, the moisture content of $\mathrm{B}-0 \% \mathrm{PBE}$ decreased up to $8.52 \%$, and the moisture content of $\mathrm{B}-50 \% \mathrm{PBE}$ decreased up to $40.12 \%$. This result indicated that the bionic design could reduce the moisture content of the chitosan film. One reason was that the bionic structure increased the surface area of the films. Another reason is that the interactions between chitosan and PBE could reduce the availability of hydroxyl and amino groups, thus limiting the interaction between chitosan and water through hydrogen bonding [15].

\subsection{Mechanical Properties}

The mechanical properties of bionic chitosan-PBE film samples were displayed in Table 3. The tensile strength of B- $0 \% \mathrm{PBE}$ was lower than the control, indicating that the bionic structure reduced the tensile strength of chitosan films. With the increase of PBE content, the tensile strength of films significantly $(p<0.05)$ improved, while there was no significant difference $(p>0.05)$ among all the films expect B- $0 \%$ PBE. Regarding the elongation at break, there were no significant differences $(p>0.05)$ between the control and the bionic chitosan-PBE films. B- $40 \% \mathrm{PBE}$ possessed the highest value that increased up to $26.83 \%$ in comparison with B- $0 \%$ PBE. These results suggested that PBE improved tensile strength and elongation at break of the bionic films. Similar results were found by Yan et al. [35], who found that adding butterfly pudding extract to the chitosan film also improved the tensile strength and elongation at break of the film. Mechanical properties are mainly related to the type and content of active compounds, the type of polymer matrix, and the specific interaction between different components [36].

Table 3. Mechanical properties of film samples.

\begin{tabular}{ccc}
\hline Films & Tensile Strength (Mpa) & Elongation at Break (\%) \\
\hline Control & $10.15 \pm 0.30^{\mathrm{b}}$ & $31.45 \pm 4.31^{\mathrm{ab}}$ \\
B-0\%PBE & $5.68 \pm 0.94^{\mathrm{a}}$ & $27.46 \pm 4.52^{\mathrm{a}}$ \\
B-30\%PBE & $10.98 \pm 0.84^{\mathrm{b}}$ & $31.79 \pm 3.23^{\mathrm{a}}$ \\
B-40\%PBE & $11.72 \pm 1.07^{\mathrm{b}}$ & $34.83 \pm 4.88^{\mathrm{b}}$ \\
B-50\%PBE & $12.36 \pm 2.88^{\mathrm{b}}$ & $32.85 \pm 2.47^{\mathrm{ab}}$
\end{tabular}

Values are given as mean \pm standard error. Different letters in the same row indicate significant differences $(p<0.05)$.

\subsection{Color Properties}

The result of color values of bionic chitosan-PBE films with different PBE concentrations were showed in Table 4 . There was no significant $(p<0.05)$ difference between the control and $\mathrm{B}-\mathrm{0} \% \mathrm{PBE}$ in all color parameters, which indicated that the bionic design does not affect the color of the chitosan films. With the increase of PBE concentration, the value of $L^{*}, b^{*}$, and $C^{*}$ decreased significantly $(p<0.05)$, which indicated that the film tended to be dark and blue. Moreover, incorporation of PBE significantly $(p<0.05)$ increased the $\mathrm{a}^{*}$ and $\Delta E$ values, which indicating that the film has a tendency toward redness. Compared with the carboxymethyl chitosan film incorporated with corn peptide, the bionic chitosan-PBE films in this study showed darker, redder, and bluer color [25]. 
Table 4. Color values of film samples.

\begin{tabular}{cccccc}
\hline Films & $\boldsymbol{L}^{*}$ & $\boldsymbol{A}^{*}$ & $\boldsymbol{B}^{*}$ & $\Delta \boldsymbol{E}^{*}$ & $\boldsymbol{C}^{*}$ \\
\hline Control & $78.05 \pm 2.28^{\mathrm{c}}$ & $0.71 \pm 1.31^{\mathrm{a}}$ & $41.57 \pm 5.17^{\mathrm{b}}$ & $46.00 \pm 0.80^{\mathrm{a}}$ & $41.59 \pm 5.17^{\mathrm{b}}$ \\
$\mathrm{B}-0 \% \mathrm{PBE}$ & $77.51 \pm 1.69^{\mathrm{c}}$ & $1.19 \pm 0.87^{\mathrm{a}}$ & $39.79 \pm 2.00^{\mathrm{b}}$ & $46.19 \pm 0.67^{\mathrm{a}}$ & $39.81 \pm 2.03^{\mathrm{b}}$ \\
$\mathrm{B}-30 \% \mathrm{PBE}$ & $20.23 \pm 2.50^{\mathrm{b}}$ & $5.29 \pm 1.56^{\mathrm{b}}$ & $1.14 \pm 0.67^{\mathrm{a}}$ & $86.02 \pm 2.11^{\mathrm{b}}$ & $5.42 \pm 1.67^{\mathrm{a}}$ \\
$\mathrm{B}-40 \% \mathrm{PBE}$ & $16.75 \pm 1.07^{\mathrm{a}}$ & $6.20 \pm 0.96^{\mathrm{bc}}$ & $0.88 \pm 0.57^{\mathrm{a}}$ & $89.09 \pm 0.89^{\mathrm{c}}$ & $6.28 \pm 0.97^{\mathrm{a}}$ \\
B-50\%PBE & $15.43 \pm 0.88^{\mathrm{a}}$ & $7.28 \pm 1.26^{\mathrm{c}}$ & $-0.22 \pm 0.27^{\mathrm{a}}$ & $90.34 \pm 0.82^{\mathrm{c}}$ & $7.29 \pm 1.26^{\mathrm{a}}$ \\
\hline
\end{tabular}

Values are given as mean \pm standard error. Different letters in the same row indicate significant differences $(p<0.05)$.

\section{Conclusions}

The results of this study suggested that the bionic structure of dragonfly wings and PBE has a considerable influence on the physicochemical properties and biological activity of the bionic chitosan-PBE film. The bionic structure increased the thickness and opacity of the film and decreased the moisture content, mechanical properties, and water vapor permeability of the film. Moreover, the addition of PBE in chitosan films with bionic structure improved the thickness, opacity, mechanical properties, and antioxidant activity of the film, but reduced the WVP of the film. Compared with the control film, the thickness, opacity, tensile strength, and DPPH free scavenging activity of bionic chitosan-PBE film increased up to $68.25 \%, 9.31$ times, $21.77 \%$, and 13.11 times, respectively, and WVP and moisture content decreased by $59.49 \%$ and $40.12 \%$, respectively. Since the antioxidant activity of the film has increased and the water vapor permeability has decreased, this is beneficial to the application of the film in active food packaging. Further research is still needed, such as the inhibition of some microorganisms and the analysis of food shelf life.

Author Contributions: Preparation of films and writing of the manuscript, K.W.; characterization of films and data analysis, M.C.; drawing and discussion, X.T.; interpretation of data and editing, M.F. and L.R.; review and approval for submission of the manuscript, L.W. All authors have read and agreed to the published version of the manuscript.

Funding: This research was supported by Opening Project of the Key Laboratory of Bionic Engineering (Ministry of Education), Jilin University (KF20200006).

Institutional Review Board Statement: Not applicable.

Informed Consent Statement: Not applicable.

Data Availability Statement: Data are contained within the current manuscript.

Conflicts of Interest: The authors declare no conflict of interest.

\section{References}

1. Microplastics, Microbeads and single-use plastics poisoning sea life and affecting humans. Available online: https://news.un. org/en/story/2019/11/1050511 (accessed on 8 August 2021).

2. Siripatrawan, U.; Vitchayakitti, W. Improving functional properties of chitosan films as active food packaging by incorporating with propolis. Food Hydrocoll. 2016, 61, 695-702. [CrossRef]

3. Zhang, S.; Li, M.; Wang, R.; Chang, L.; Ju, H.; Lin, W.; Zhao, W.; Tang, Y.; Lin, S. Superhydrophobic and antioxidative film based on edible materials for food packaging. Langmuir 2021, 37, 5066-5072. [CrossRef]

4. Dong, Z.; Li, R.; Gong, Y. Antibacterial and freshness-preserving mechanisms of chitosan-nano-TiO ${ }_{2}$-nano-Ag composite materials. Coatings 2021, 11, 914. [CrossRef]

5. Gao, L.; Zhu, T.; He, F.; Ou, Z.; Xu, J.; Ren, L. Preparation and characterization of functional films based on chitosan and corn starch incorporated tea polyphenols. Coatings 2021, 11, 817. [CrossRef]

6. Jakubowska, E.; Gierszewska, M.; Nowaczyk, J.; Olewnik-Kruszkowska, E. The role of a deep eutectic solvent in changes of physicochemical and antioxidative properties of chitosan-based films. Carbohyd. Polym. 2021, 255, 117527. [CrossRef]

7. Pyo, Y.C.; Tran, P.; Kim, D.H.; Park, J.S. Chitosan-coated nanostructured lipid carriers of fenofibrate with enhanced oral bioavailability and efficacy. Colloid Surf. B 2020, 196, 111331. [CrossRef]

8. Kanatt, S.R.; Chander, R.; Sharma, A. Chitosan and mint mixture: A new preservative for meat and meat products. Food Chem. 2008, 107, 845-852. [CrossRef] 
9. Yan, T.; Li, C.; Ouyang, Q.; Zhang, D.; Zhong, Q.; Li, P.; Li, S.; Yang, Z.; Wang, T.; Zhao, Q. Synthesis of gentamicin-grafted-chitosan with improved solubility and antibacterial activity. React. Funct. Polym. 2019, 137, 38-45. [CrossRef]

10. Mehdizadeh, T.; Tajik, H.; Langroodi, A.M.; Molaei, R.; Mahmoudian, A. Chitosan-starch film containing pomegranate peel extract and Thymus kotschyanus essential oil can prolong the shelf life of beef. Meat Sci. 2020, 163, 108073. [CrossRef]

11. Kõrge, K.; Bajić, M.; Likozar, B.; Novak, U. Active chitosan-chestnut extract films used for packaging and storage of fresh pasta. Int. J. Food Sci. Tech. 2020, 55, 3043-3052. [CrossRef]

12. Liu, Z.; Du, M.; Liu, H.; Zhang, K.; Xu, X.; Liu, K.; Tu, J.; Liu, Q. Chitosan films incorporating litchi peel extract and titanium dioxide nanoparticles and their application as coatings on watercored apples. Prog. Org. Coat. 2021, 151, 106103. [CrossRef]

13. Grimm, T.; Schäfer, A.; Högger, P. Antioxidant activity and inhibition of matrix metalloproteinases by metabolites of maritime pine bark extract (pycnogenol). Free Radic. Biol. Med. 2004, 36, 811-822. [CrossRef]

14. Karakaya, P.S.; Oktay, A.; Seventekin, N.; Yesil-Celiktas, O. Design of a new generation wound dressing with pine bark extract. J. Ind. Text. 2021, 50, 1193-1204. [CrossRef]

15. Devaraj, S.; Vega-López, S.; Kaul, N.; Schönlau, F.; Rohdewald, P.; Jialal, I. Supplementation with a pine bark extract rich in polyphenols increases plasma antioxidant capacity and alters the plasma lipoprotein profile. Lipids 2002, 37, 931-934. [CrossRef]

16. Ren, L.; Yan, X.; Zhou, J.; Tong, J.; Su, X. Influence of chitosan concentration on mechanical and barrier properties of corn starch/chitosan films. Int. J. Biol. Macromol. 2017, 105, 1636-1643. [CrossRef]

17. Wang, L.; Guo, H.; Wang, J.; Jiang, G.; Du, F.; Liu, X. Effects of Herba Lophatheri extract on the physicochemical properties and biological activities of the chitosan film. Int. J. Biol. Macromol. 2019, 133, 51-57. [CrossRef]

18. Bai, R.; Zhang, X.; Yong, H.; Wang, X.; Liu, Y.; Liu, J. Development and characterization of antioxidant active packaging and intelligent Al3+-sensing films based on carboxymethyl chitosan and quercetin. Int. J. Biol. Macromol. 2019, 126, $1074-1084$. [CrossRef]

19. Wang, L.; Dong, Y.; Men, H.; Tong, J.; Zhou, J. Preparation and characterization of active films based on chitosan incorporated tea polyphenols. Food Hydrocoll. 2013, 32, 35-41. [CrossRef]

20. Liu, T.; Wang, J.; Chi, F.; Tan, Z.; Liu, L. Development and characterization of novel active chitosan films containing fennel and peppermint essential oils. Coatings 2020, 10, 936. [CrossRef]

21. Fan, J.S.; Lee, I.J.; Lin, Y.L. Flavone glycosides from commercially available Lophatheri Herba and their chromatographic fingerprinting and quantitation. J. Food Drug Anal. 2015, 23, 821-827. [CrossRef]

22. Sun, L.; Sun, J.; Chen, L.; Niu, P.; Yang, X.; Guo, Y. Preparation and characterization of chitosan film incorporated with thinned young apple polyphenols as an active packaging material. Carbohyd. Polym. 2017, 163, 81-91. [CrossRef]

23. Liu, T.; Liu, L.; Gong, X.; Chi, F.; Ma, Z. Fabrication and comparison of active films from chitosan incorporating different spice extracts for shelf life extension of refrigerated pork. LWT-Food Sci. Technol. 2021, 135, 110181. [CrossRef]

24. Salama, H.E.; Aziz, M.S.A.; Sabaa, M.W. Development of antibacterial carboxymethyl cellulose/chitosan biguanidine hydrochloride edible films activated with frankincense essential oil. Int. J. Biol. Macromol. 2019, 139, 1162-1167. [CrossRef]

25. Liu, J.; Liu, S.; Wu, Q.; Gu, Y.; Kan, J.; Jin, C. Effect of protocatechuic acid incorporation on the physical, mechanical, structural and antioxidant properties of chitosan film. Food Hydrocoll. 2017, 73, 90-100. [CrossRef]

26. Wang, L.; Lei, L.; Wan, K.; Fu, Y.; Hu, H. physicochemical properties and biological activity of active films based on corn peptide incorporated carboxymethyl chitosan. Coatings 2021, 11, 604. [CrossRef]

27. Kadam, A.A.; Singh, S.; Gaikwad, K.K. Chitosan based antioxidant films incorporated with pine needles (Cedrus deodara) extract for active food packaging applications. Food Control 2021, 124, 107877. [CrossRef]

28. Romani, V.P.; Martins, V.G.; Goddard, J.M. Radical scavenging polyethylene films as antioxidant active packaging materials. Food Control 2020, 109, 106946. [CrossRef]

29. Meng, W.; Shi, J.; Zhang, X.; Lian, H.; Wang, Q.; Peng, Y. Effects of peanut shell and skin extracts on the antioxidant ability, physical and structure properties of starch-chitosan active packaging films. Int. J. Biol. Macromol. 2020, 152, 137-146. [CrossRef]

30. Riaz, A.; Lagnika, C.; Luo, H.; Dai, Z.; Nie, M.; Hashim, M.M.; Li, D. Chitosan-based biodegradable active food packaging film containing Chinese chive (Allium tuberosum) root extract for food application. Int. J. Biol. Macromol. 2020, 150, 595-604. [CrossRef]

31. Soni, B.; Schilling, M.W.; Mahmoud, B. Transparent bionanocomposite films based on chitosan and TEMPO-oxidized cellulose nanofibers with enhanced mechanical and barrier properties. Carbohyd. Polym. 2016, 151, 779-789. [CrossRef]

32. Wang, L.; Wang, Q.; Tong, J.; Zhou, J. Physicochemical properties of chitosan films incorporated with honeysuckle flower extract for active food packaging. J. Food Process Eng. 2017, 40, e12305. [CrossRef]

33. Siripatrawan, U.; Harte, B.R. Physical properties and antioxidant activity of an active film from chitosan incorporated with green tea extract. Food Hydrocoll. 2010, 24, 770-775. [CrossRef]

34. Riaz, A.; Lei, S.; Akhtar, H.M.S.; Wan, P.; Chen, D.; Jabbar, S.; Abid, M.; Hashim, M.M.; Zeng, X. Preparation and characterization of chitosan-based antimicrobial active food packaging film incorporated with apple peel polyphenols. Int. J. Biol. Macromol. 2018, 114, 547-555. [CrossRef] [PubMed]

35. Yan, J.; Cui, R.; Qin, Y.; Li, L.; Yuan, M. A pH indicator film based on chitosan and butterfly pudding extract for monitoring fish freshness. Int. J. Biol. Macromol. 2021, 177, 328-336. [CrossRef] [PubMed]

36. Hu, F.; Sun, T.; Xie, J.; Xue, B.; Li, X.; Gan, J.; Li, L.; Bian, X.; Shao, Z. Functional properties of chitosan films with conjugated or incorporated salicylic acid. J. Mol. Struct. 2021, 1223, 129237. [CrossRef] 